\title{
Micro XRF Imaging of Daguerreotypes
}

Jeffrey M. Davis ${ }^{1}$, Connor Hilton ${ }^{2,3}$, and Edward P. Vicenzi ${ }^{1,3}$

${ }^{1}$ National Institute of Standards and Technology, 100 Bureau Drive, Gaithersburg, MD 20899

${ }^{2}$ Brown University, Geological Sciences, Providence, RI 02912

${ }^{3}$ Smithsonian Institution, Museum Conservation Institute, Suitland, MD 20746

Daguerreotype photography represents the first practical method for producing images in the mid-19 century. The process involved polishing a silver coated copper plate, made photo sensitive by exposure to halogens, then exposed to light, and finally coated with gold. This complex, intricate process has yielded some of the most iconic images of the $19^{\text {th }}$ century. Unfortunately, in some instances plate interaction with storage materials have yielded objects ranging from pristine to disfigured. While damage is often apparent from visual inspection, the precise method of deterioration - and thus the elucidation of methods of restoration, if desirable - is sometimes, but not always apparent.

Micro focused X-ray fluorescence imaging ( $\mu \mathrm{XRF}$ ) has been applied to numerous objects within cultural heritage [1]. The non-destructive nature of the X-rays, coupled with the possibility of chemical imaging at atmospheric pressure has been particularly useful. In the case of the daguerreotypes, low vacuum pressures were not deemed likely to damage the sample, and were successfully used to improve the detection of lower energy X-rays, e.g. Au M lines.

Images produced by the $\mu \mathrm{XRF}$ are useful because they provide sufficient imaging detail on the scale of the of the entire specimen (many $\mathrm{cms}$ ). Additionally, they provide key information about the degradation processes. Shown in Figure 1, the optical images (Figures 1 A,C) and the $\mu$ XRF images (Figures $1 \mathrm{~B}, \mathrm{D}$ thermal scaled $\mathrm{Au}-\mathrm{Hg} \mathrm{M}$ family image) reveal details about the image and the thickness of the gold gilding. Highlighted object damage (yellow ellipses) is less apparent in the X-ray images.

Figure 2 illustrates one of the measurement challenges regarding the separation of the $\mathrm{Au}, \mathrm{Hg}$, and $\mathrm{S}$ lines in the region between approximately $2 \mathrm{keV}$ and $2.5 \mathrm{keV}$. Using DTSA II spectral fitting software, the peaks were deconvolved. Deconvolution of this region is required to isolate the $\mathrm{S}$ image which relates to tarnishing as atmospheric $\mathrm{S}$ is taken up at the surface.

\section{References:}

[1] Monico, L., et al. Analytical Chemistry 83 (2011), p. 1224. 

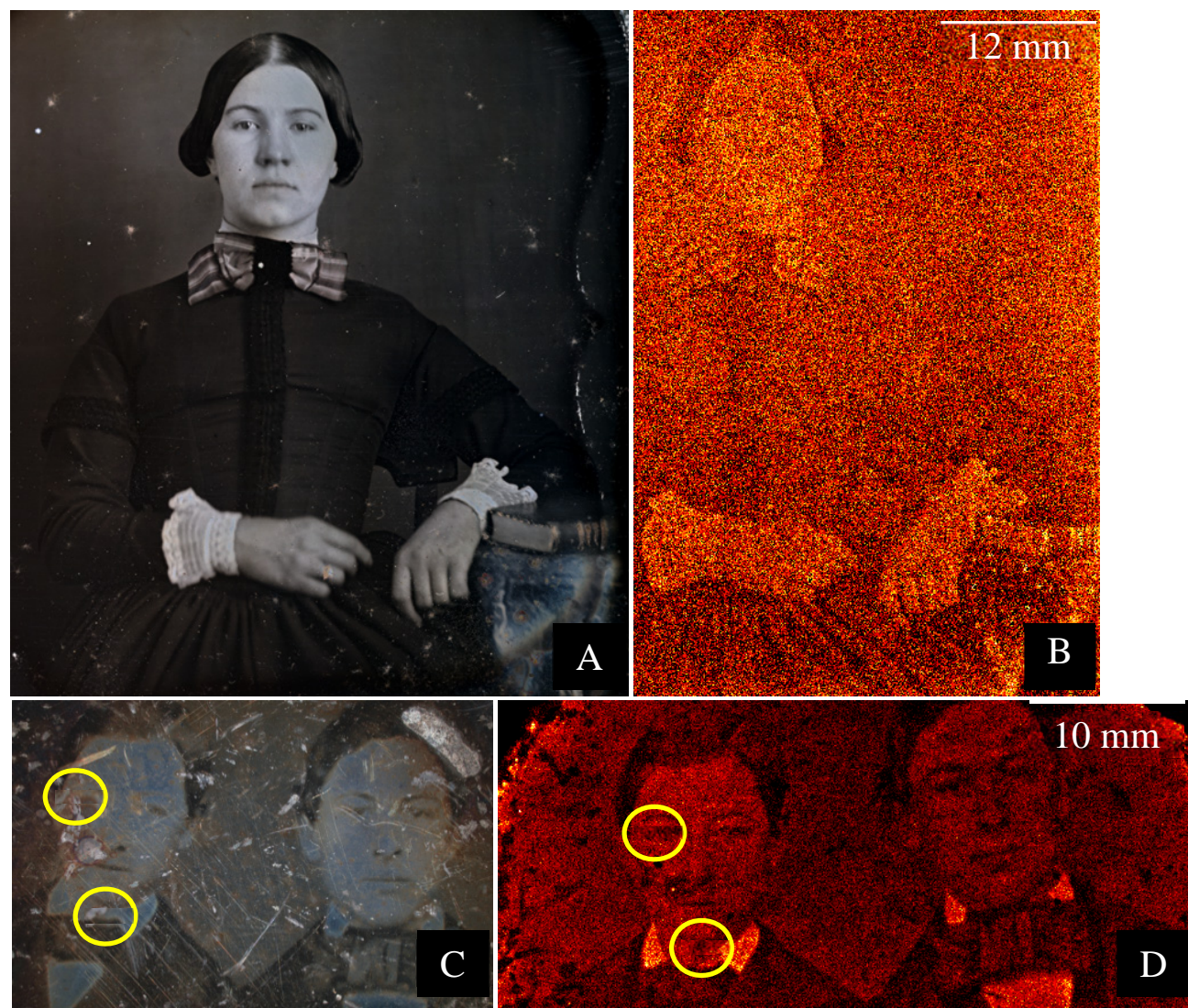

Figure 1. A ) Well-preserved $19^{\text {th }}$ century daguerreotype photograph, B) Au M and Hg M sum image, C) Poorly preserved $19^{\text {th }}$ century daguerreotype photograph, D) Au M and $\mathrm{Hg} \mathrm{M}$ sum image.

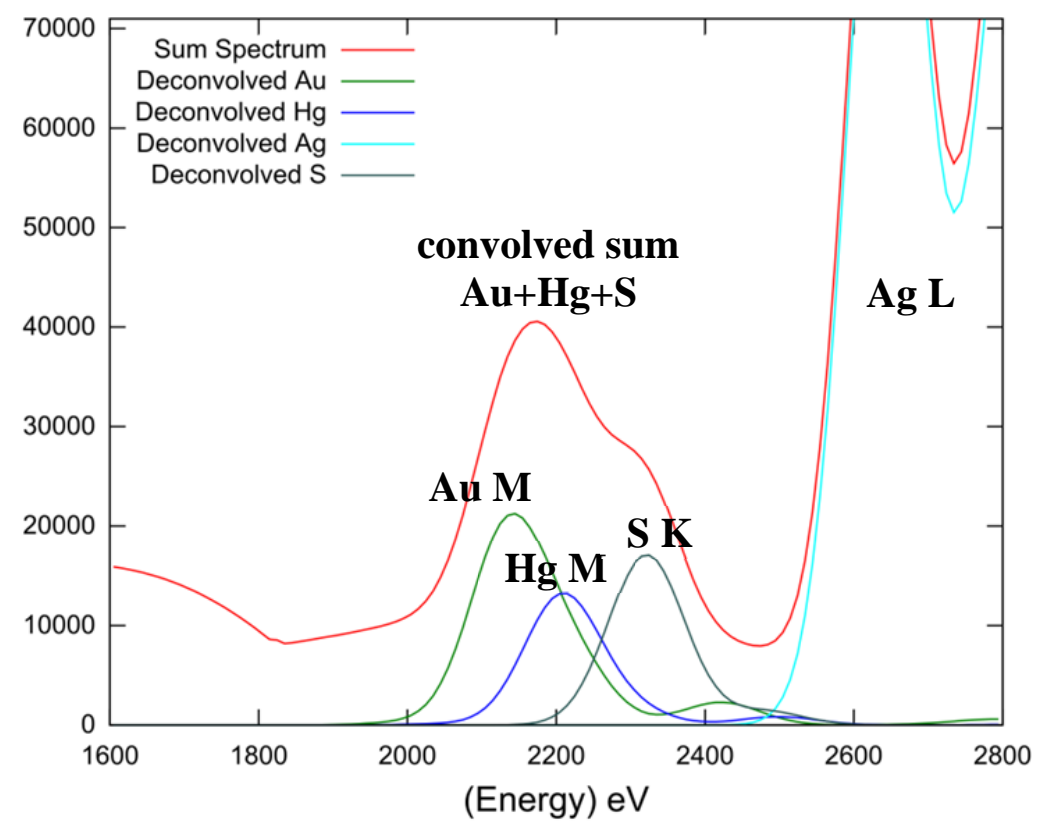

Figure 2. XRF spectrum in the energy region where $\mathrm{Au} \mathrm{M-,} \mathrm{Hg} \mathrm{M}$-, and $\mathrm{S} \mathrm{K}$-lines are significantly convolved. 